\title{
Spatial variability of the parameters of a semi-distributed hydrological model
}

\author{
Alban de Lavenne, Guillaume Thirel, Vazken Andréassian, Charles Perrin, and Maria-Helena Ramos \\ Irstea, Hydrosystems and Bioprocesses Research Unit (HBAN), 1, rue Pierre-Gilles de Gennes, CS 10030, \\ 92761 Antony Cedex, France \\ Correspondence to: Alban de Lavenne (alban.de-lavenne@irstea.fr) \\ Published: 12 May 2016
}

\begin{abstract}
Ideally, semi-distributed hydrologic models should provide better streamflow simulations than lumped models, along with spatially-relevant water resources management solutions. However, the spatial distribution of model parameters raises issues related to the calibration strategy and to the identifiability of the parameters. To analyse these issues, we propose to base the evaluation of a semi-distributed model not only on its performance at streamflow gauging stations, but also on the spatial and temporal pattern of the optimised value of its parameters. We implemented calibration over 21 rolling periods and 64 catchments, and we analysed how well each parameter is identified in time and space. Performance and parameter identifiability are analysed comparatively to the calibration of the lumped version of the same model. We show that the semi-distributed model faces more difficulties to identify stable optimal parameter sets. The main difficulty lies in the identification of the parameters responsible for the closure of the water balance (i.e. for the particular model investigated, the intercatchment groundwater flow parameter).
\end{abstract}

\section{Introduction}

\subsection{What hydrological good sense suggests}

Developing modelling tools that help to understand the spatial distribution of water resources is a key issue for better management. The dynamics of streamflow depends on (i) the spatial variability of precipitation (which, a priori, should be better handled by a semi-distributed hydrological model), (ii) the heterogeneity of catchment behavior (which can be dealt explicitly with by spatially-variable model parameters), and, increasingly, (iii) localized human regulations (for instance, water reservoirs). Since calibration is generally based on discharge measurements at the outlet of the catchment only, and gauging stations are not available everywhere, semi-distributed hydrological models are often difficult to parameterize. As argued by Pokhrel and Gupta (2011), difficulties are due to the smoothing effect of catchments and to the dispersive effect of flow routing combined with numerical issues and measurement uncertainty. The authors state that the impact of spatial variability could become "virtually non-detectable by conventional performance measures by the time the water reaches the catchment outlet".

This raises the need to better understand how well parameters are identified in a semi-distributed model compared to a lumped model. The variability of catchment model parameters calibrated over different periods ("time variability") is one way of approaching this question. Indeed, as reminded by Merz et al. (2011), parameters of a rainfall-runoff model are supposed to represent stable catchment conditions, while the time-varying conditions are supposed to be triggered by the time-series of meteorological inputs. Thus, optimised parameter values should not be overly sensitive to changes of climatic conditions, and one would expect a semi-distributed model to be more stable than a lumped one (because the parameters of the lumped model would have to account implicitly for changing spatial precipitation patterns).

\subsection{What the literature says}

However, literature provides many examples showing that this assumption is hardly satisfied. Merz et al. (2011) raise two main difficulties. First, problems in model structure and 
data measurements tend to be compensated by calibration. For instance, Wagener et al. (2003) identify inconsistencies in the structure of a rainfall-runoff model by highlighting instabilities of the optimal values of the parameters between periods with and without rainfall events. In contrast, Juston et al. (2009) found that data subset of their input data (from daily to quaterly sampling intervals) can provide very similar constraints on model calibration and parameter identification.

Secondly, conditions of the catchment itself may change over time, which consequently, and understandably, shifts optimal model parameters, and justifies rigourous evaluations of the model robustness (Thirel et al., 2015). For instance, changes of land use might directly impact optimal parameter sets (Andréassian et al., 2003; Brown et al., 2005; Verstegen et al., 2016). Trends on parameters can also be related to changes in climatic conditions (Merz et al., 2006; Merz and Blöschl, 2009). On a study based on 273 Austrian catchments, Merz et al. (2011) attribute a doubling of the parameter that controls runoff generation in their model to be related to hydrological changes (such as higher evapotranspiration and drier catchment conditions) rather than calibration artifacts. For about one third of 17 African catchments, Niel et al. (2003) find their model parameters to be unstable, but they did not identify any climate-related reason. Wilby (2005) analyses this question in the context of climate change impact assessment for the River Thames. The author finds model parameters to be highly sensitive to training periods, and recommends the quantitification of those large uncertainties due to parameter instability, identifiability and nonuniqueness. Similarly, Brigode et al. (2013) found that the uncertainty due to the climate characteristics of the calibration period is larger than the uncertainty in the estimation of parameters that is often quantified on the basis of Bayesian inference. They attribute this finding to a lack of robustness of the model and recommend more efforts to be put into this aspect.

\subsection{Scope of the paper}

This paper investigates the procedure of parameter identifiability in a semi-distributed model by comparing model calibration schemes and results with a lumped model on which it is based. From this comparison, we address two main questions: (1) Does spatial distribution of parameters interfere with parameters identifiability? Indeed, one could hope that applying parameters to a more geographically-limited area tends to facilitate their identification. (2) What are the parameters that are the most variable in the lumped and in the semi-distributed models? In this way, we aim to diagnose which components of the model are the least robust, in the sense that their parameterisation is difficult to transpose in time and space.

\section{Material and methods}

\subsection{Study area and hydro-meteorological data}

The model is implemented in Eastern France, close to the border with Germany, over 64 sub-catchments of French tributaries of the River Rhine (Fig. 1), namely the rivers Moselle, Sarre and the smaller tributaries of the Rhine located in the Vosges massif. Catchments size vary from 27 to $770 \mathrm{~km}^{2}$ and this represents a total area of about $4340 \mathrm{~km}^{2}$. Climate is predominantly oceanic with continental influence. Annual precipitation $(P)$ varies from about $700 \mathrm{~mm}$ in the lowland to about $1600 \mathrm{~mm}$ in the Vosges massif. Average daily temperature $(T)$ and potential evapotranspiration (PE) in the catchment vary from 7 to $10^{\circ} \mathrm{C}$ and 540 to $690 \mathrm{~mm}$, respectively.

The two hydrological models implemented (lumped and semi-distributed) require daily time series of $P$ and PE as input data. We used climate data from the SAFRAN meteorological reanalysis of Météo-France (Vidal et al., 2010), which is provided on a square grid of $8 \mathrm{~km} \times 8 \mathrm{~km}$. Discharge data were extracted from the French Hydro database (Leleu et al., 2014) at the daily time step. They were used to perform the calibration and the evaluation of the models. The study period is 1971-2000.

\subsection{The GR5J lumped and GRSD semi-distributed rainfall-runoff models}

The GRSD semi-distributed rainfall-runoff model was developed by Lerat (2009) and Lobligeois (2014). It is based on the GR5J lumped model (Fig. 2) proposed by Le Moine (2008), which has five free parameters to calibrate (Table 1). The main components of the model are two stores: a production store (with maximum capacity $\mathrm{X} 1$ ) and a routing store (capacity X3), which is filled by the output of a unit hydrograph (of time base X4). Two other parameters, X2 and X5, are used to quantify the intercatchment groundwater flows (IGF). In order to account for snow accumulation and melt, the model is combined with a degree-day snow module (Valéry et al., 2014), which contains two additional parameters $\left(C_{\mathrm{TG}}\right.$ and $\left.K_{\mathrm{f}}\right)$. However, in our study, these parameters were not calibrated and fixed at their default values, respectively set at 0.2 and $4.5 \mathrm{~mm}^{\circ} \mathrm{C}^{-1}$, as proposed by previous studies in France (Valéry et al., 2014).

The semi-distributed model is applied on sub-catchments. The delineation of sub-catchments is performed only at gauging stations, which means that discharge measurements are available for every hydrological units of the model. The lumped GR5J model is applied on hydrological units composed of upstream catchments (headwater catchments) or intermediate sub-catchments (drained area between downstream and upstream stations). In that way, each hydrological unit receives its own meteorological inputs $(P$ and $\mathrm{PE})$ and uses a distinct parameter set (see Sect. 2.3.2). 

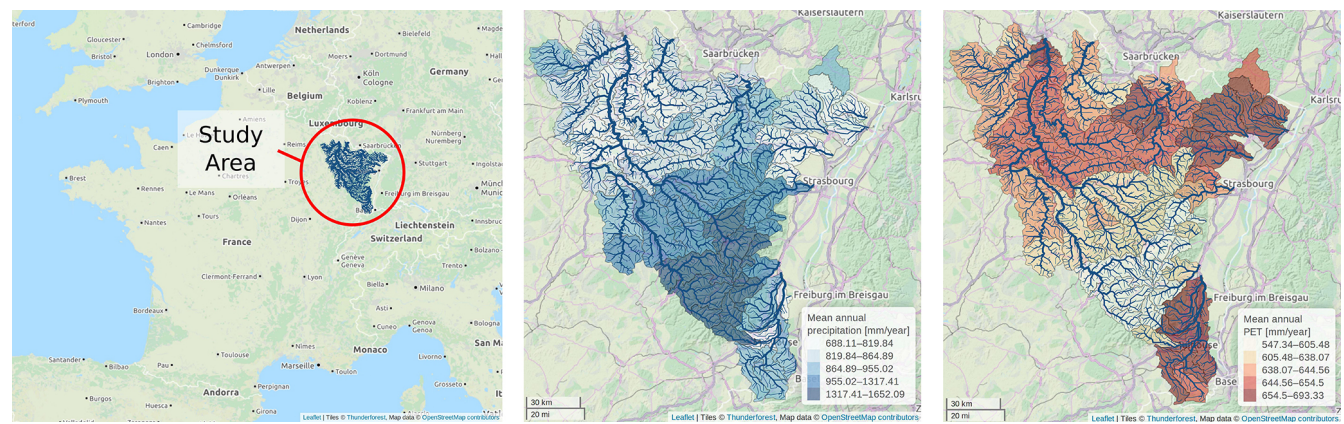

Figure 1. Location of the study area (left), and average annual precipitation (centre) and annual potential evapotranspiration (right) for each sub-catchment (climate data are estimated from the 1971-2000 SAFRAN database).

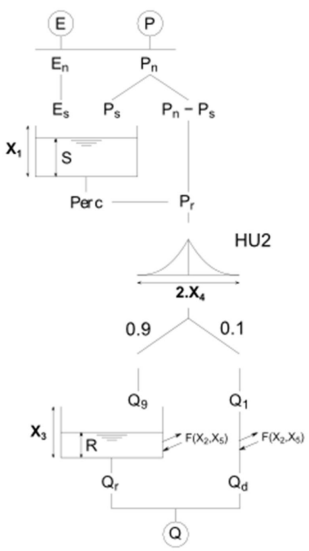

(a) GR5J

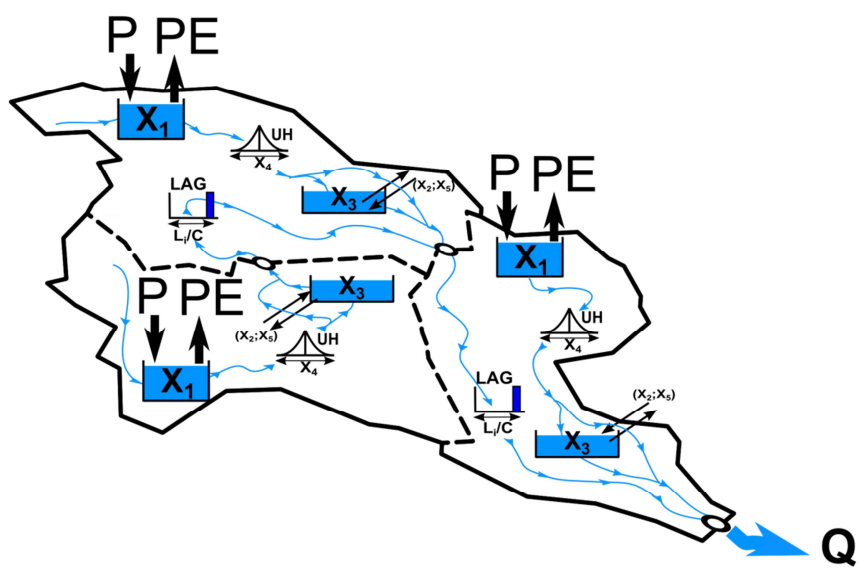

(b) GRSD

Figure 2. Schematic representation of the GR5J and GRSD semi-distributed model (from Lobligeois et al., 2014).

Table 1. List of the parameters for the semi-distributed conceptual rainfall-runoff model GRSD.

\begin{tabular}{llll}
\hline $\begin{array}{l}\text { Model } \\
\text { parameter }\end{array}$ & GR5J & GRSD & Description \\
\hline $\mathrm{X} 1$ & Free & Free & $\begin{array}{l}\text { Production store } \\
\text { capacity }[\mathrm{mm}]\end{array}$ \\
\hline $\mathrm{X} 2$ & Free & Free & $\begin{array}{l}\text { Groundwater exchange } \\
\text { coefficient }\left[\mathrm{mm} \mathrm{d}^{-1}\right]\end{array}$ \\
\hline $\mathrm{X} 3$ & Free & Free & Routing store capacity [mm] \\
\hline $\mathrm{X} 4$ & Free & Free & Time base of the unit hydrograph [d] \\
\hline $\mathrm{X} 5$ & Free & Free & $\begin{array}{l}\text { Threshold for groundwater } \\
\text { exchange }[-]\end{array}$ \\
\hline$C$ & - & Free & Average streamflow velocity $\left[\mathrm{m} \mathrm{s}^{-1}\right]$ \\
\hline$C_{\mathrm{TG}}$ & Fixed & Fixed & $\begin{array}{l}\text { Ponderation coefficient of the snow } \\
\text { thermic state }[-]\end{array}$ \\
\hline$K_{\mathrm{f}}$ & Fixed & Fixed & Degree-day factor $\left[\mathrm{mm}^{\circ} \mathrm{C}^{-1}\right]$ \\
\hline
\end{tabular}

The outflow of each GR5J model is finally routed to its downstream catchment using a linear lag propagation model (Bentura and Michel, 1997). Previous studies have shown that this propagation model gives a satisfactory level of efficiency compared to more sophisticated channel routing methods (Lobligeois et al., 2014). This routing functionality implies an additional free parameter (compared to the lumped model GR5J) that needs to be calibrated on each hydrological unit: the average flow velocity $C$.

\subsection{Methodology}

\subsubsection{Goodness of fit criteria}

In order to quantify the agreement between simulations $(S)$ and observations $(O)$, we used the Kling-Gupta Efficiency (KGE) (Gupta et al., 2009), which is based on a decomposition of the Nash-Sutcliffe efficiency (Nash and Sutcliffe, 1970). Moreover, in order to evaluate performances on high and low flows, we used an objective function $\mathrm{KGE}_{\mathrm{m}}$ composed of two criteria (Eq. 1): a KGE applied on discharge values to emphasize high flows and a KGE applied on inverse discharge values to emphasize low flows. Both criteria 
are applied on the selected discharge time series. Similarly to the KGE criteria, $\mathrm{KGE}_{\mathrm{m}}$ varies between $-\infty$ and 1 , which is its optimal value.

$\operatorname{KGE}_{\mathrm{m}}(S, O)=0.5 \cdot\left(\operatorname{KGE}(S, O)+\operatorname{KGE}\left(\frac{1}{S+\epsilon}, \frac{1}{O+\epsilon}\right)\right)$,

where $O$ and $S$ are the observed and simulated discharges. In order to face numerical problems in case of zero discharge when using the inverse transformation, an $\epsilon$ constant is used and set to $1 \%$ of the mean value of $O$ (Pushpalatha et al., 2012).

\subsubsection{Calibration strategy of the semi-distributed model}

Following Lerat et al. (2012), we performed a multi-site calibration of the GRSD semi-distributed model. Streamflow data at interior points are used to calibrate the model at one outlet. Each intermediate catchment is allowed to have a different parameter set. This is done sequentially, from upstream to downstream points: once the upstream catchment is calibrated, its parameters remain fixed during the calibration of the downstream intermediate catchment.

Sequential calibration is a common strategy for semidistributed models (see e.g., Andersen et al., 2001; Moussa et al., 2007). It needs as much calibration runs as there are interior points. However, it only uses successive single objective functions, rather than using multi-response objective function to optimize every interior points simultaneously.

\subsubsection{Rolling calibration periods}

Similarly to Coron et al. (2012), we calibrated the parameters using 10-year long consecutive periods between 1971 and 2000, and used the rest of the time series (20 years) for validation (Fig. 3). This is equivalent to 21 split-sample tests (Klemeš, 1986) performed every year.

Following the work of Merz and Blöschl (2009) and Merz et al. (2011), this enables to provide 21 parameter sets for each of the 64 catchments in order to analyse the temporal and spatial changes of the calibrated parameters. This testing strategy is applied to both models, the lumped model and the semi-distributed model. Parameter variability can thus be compared between the two modelling strategies.

\section{Results and discussion}

\subsection{Performance of the streamflow simulations}

The comparison of the goodness-of-fit between the lumped GR5J model and the semi-distributed GRSD model shows slightly better results of the lumped model during calibration and identical results during validation (Fig. 4). One would expect higher performances of the semi-distributed model because it accounts for spatial heterogeneities and nonlinearities that can influence the response of the system. How-

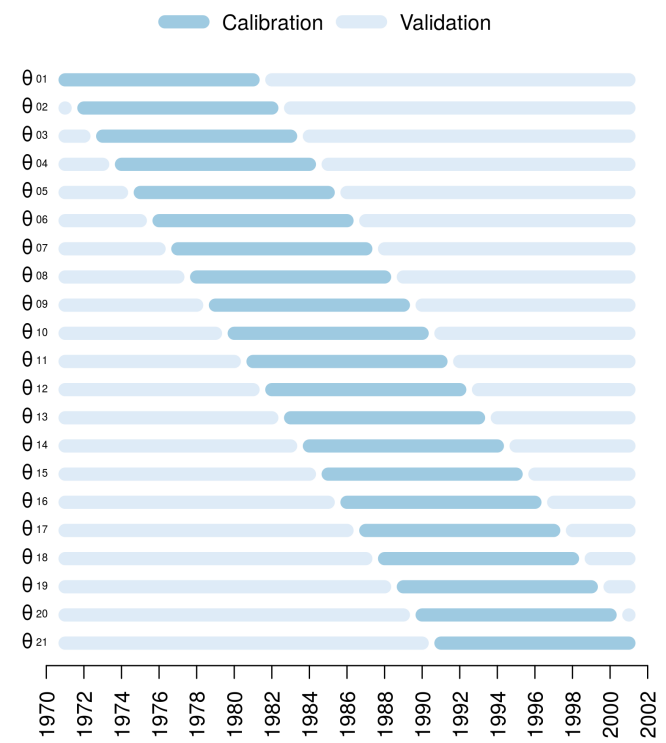

Figure 3. Illustration of the rolling calibration period methodology: 21 parameter sets $\theta$ can be identified for each catchment.

ever, literature provides numerous examples of similar results (e.g., Reed et al., 2004), where lumped models perform better. To explain such behaviour, calibration strategies, which are not as well defined for semi-distributed models as for lumped models, are often pointed out (Pokhrel and Gupta, 2011).

As expected, performance on upstream catchments are similar between the lumped and the semi-distributed catchments. Indeed, for those catchments, models are strictly identical (Sect. 2.2). Minor differences can be explained by calibration artifacts and by the fact that both models are implemented in two different modelling environments.

We did not detect any significant performance trends in time. Calibration performances are rather stable, whereas validation performances are subject to more fluctuations. These are similar between the lumped and the semidistributed models. Results illustrate that both models are potentially able to produce stable efficiency $\left(\mathrm{KGE}_{\mathrm{m}}\right)$ all along 1971-2000 period, but each calibration period does not provide the same robustness (as observed by validation).

\subsection{Temporal trends and variability of parameters}

Here, we compare the temporal trends and the variability of parameters, and differences between the two models. The distribution of parameter values according to the 21 calibration periods is given in Fig. 5.

As expected from the structure of the models (Sect. 2.2), upstream catchments have similar parameter sets for both models, whereas different optimum parameter values are obtained for downstream catchments. The main differences concern the parameter X1 (capacity of production store), which is higher for the lumped model than for the semi- 


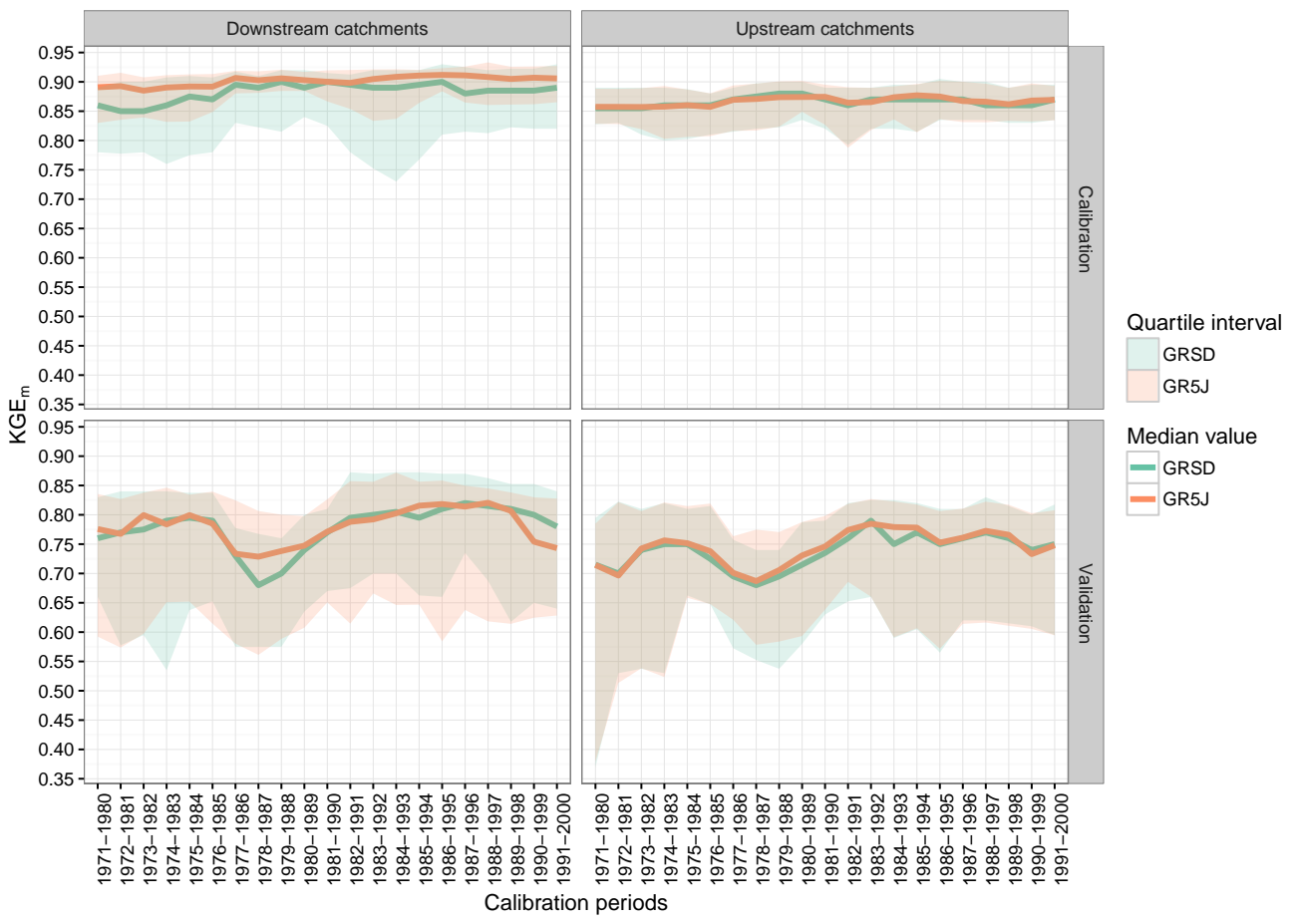

Figure 4. Quantile values of the goodness-of-fit $\left(\mathrm{KGE}_{\mathrm{m}}\right)$ during calibration and validation over the 64 catchments for the lumped model (GR5J) and the semi-distributed model (GRSD) along the 21 calibration periods. Upstream catchments are all headwater hydrological units, and downstream catchments are all the others.

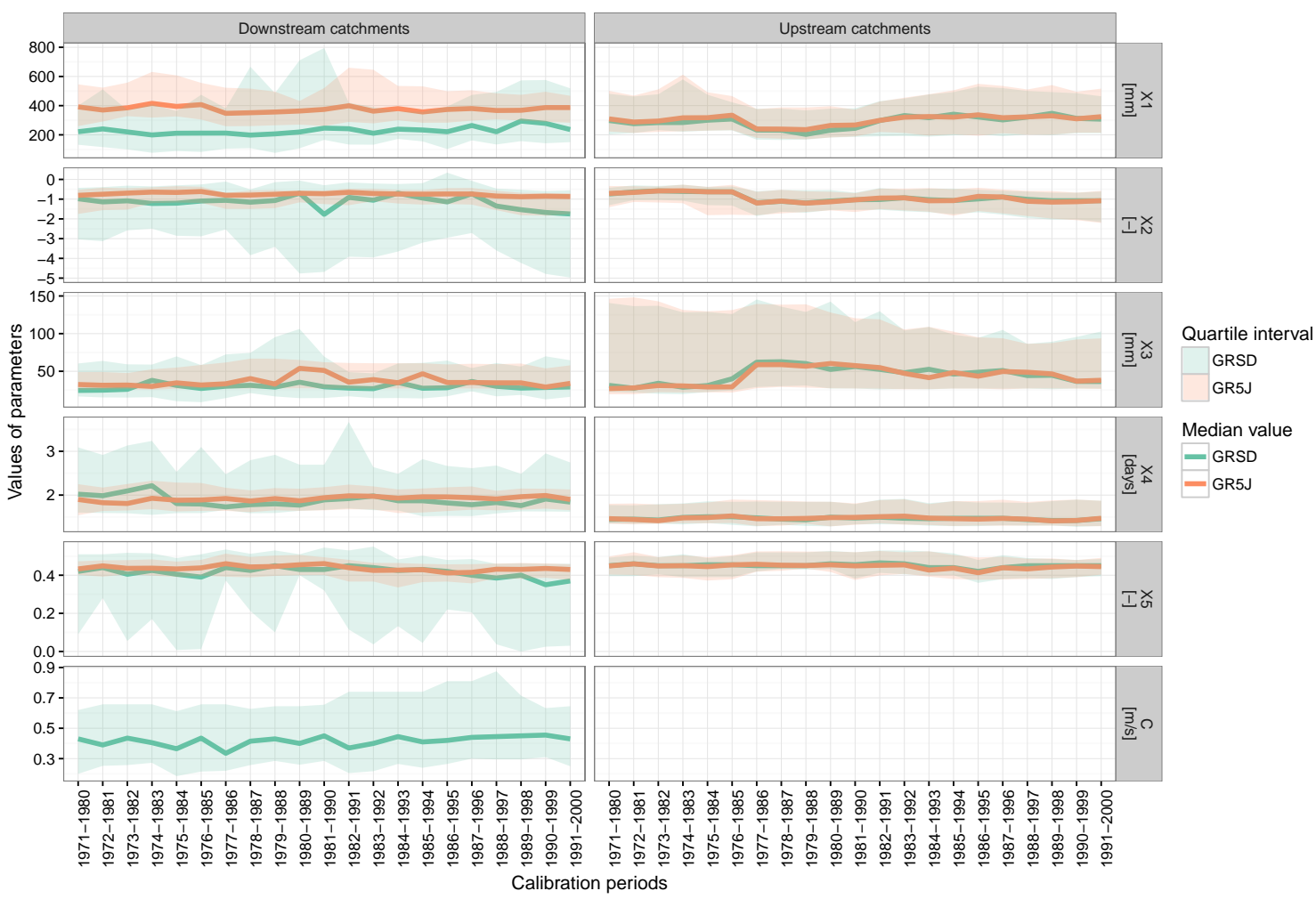

Figure 5. Quantile values of optimised parameter values according to the calibration periods for the 64 catchments. Upstream catchments are all headwater hydrological units, and downstream catchments are all the others. 


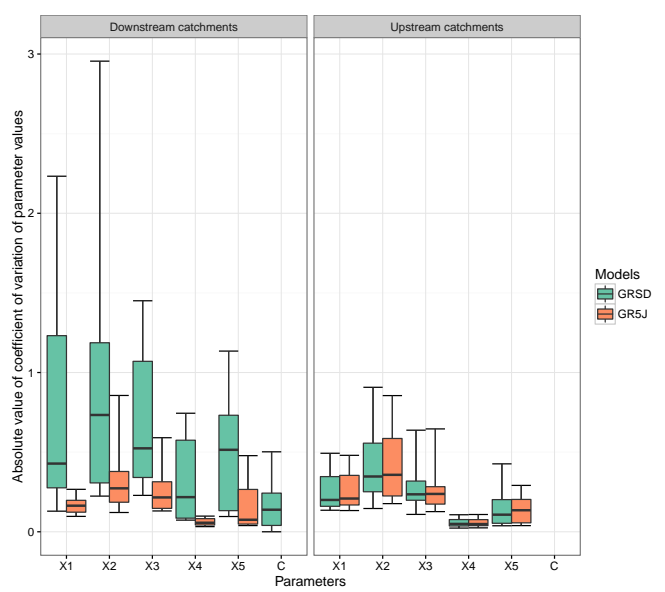

(a) Temporal variability

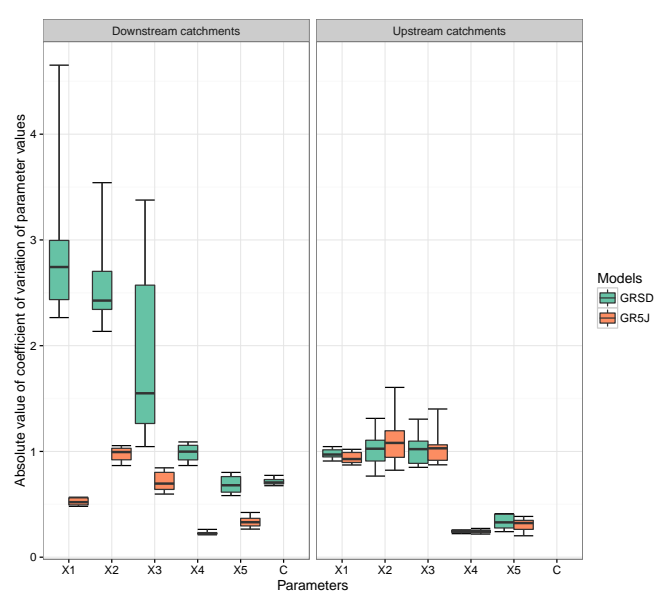

(b) Spatial variability

Figure 6. Variability of parameters values among calibration periods within one catchment (64 catchments summarized by boxplots, a) and variability of parameters values among catchments within one calibration period (21 calibration periods summarized by boxplots, b). Boxplot limits describe the 10th, 25th, 50th, 75th and 90th quantiles.

distributed model. This means a more dynamic response of the downstream hydrological units of the GRSD model and lower evapotranspiration losses. The smoothing of the hydrographs may, in fact, be achieved by the succession of responses of the sub-catchments, from upstream to downstream.

The smaller production store in GRSD appears to be compensated by $\mathrm{X} 2$ and $\mathrm{X} 5$. Indeed, those parameters aim to quantify intercatchment groundwater flows (IGF), which is the amount of water that daily gets out/in of the catchment to fill/empty the routing store and the direct flow component. The X2 parameter quantifies IGF according to a linear relation with the routing store rate $\left(\frac{S_{\text {rout }}(t)}{\mathrm{X} 3}\right)$, whereas X5 allows changing the sign of IGF during the year (Eq. 2). In GRSD, where we observe greater negative values of X2 and smaller values of X5 (Fig. 5), IGF may be higher to compensate lower evapotranspiration losses in the production store.

$\mathrm{IGF}(t)=\mathrm{X} 2 \cdot\left(\frac{S_{\text {rout }}(t)}{\mathrm{X} 3}-\mathrm{X} 5\right)$

By looking at parameter values according to the calibration periods, a relative stability of the median value appears among catchments. Only the parameters X2 and X5 in GRSD tend to slowly decrease. These trends are not observed in the lumped model, whose parameters appear more stable for downstream catchments.

From the relative stability in Fig. 5, one could conclude about overall relative robustness of the calibration. However, this does not evaluate parameter stability for each catchment. Therefore, for each hydrological unit of both models, we calculated the coefficient of variation of the parameter values using the 21 parameter sets (Fig. 6).

First, results clearly show a higher temporal variability of the parameters of the semi-distributed model, comparatively to the variability observed with the lumped model (Fig. 6). It appears that limiting the geographical extent of the area on which the parameter set is applied does not facilitate its identification. One reason for this can come from the calibration strategy, in which one sub-catchment receives simulated outflows from upstream catchments. This upstream volume of water can already represent most of the observed downstream hydrograph. Therefore, parameters applied just on a downstream intermediate sub-catchment might have a minor impact, with problems of sensitivity. Thus calibration may converge to more unstable values, which brings only small improvements to downstream simulations.

Second, it is shown that the most important temporal instability of parameter values is related to the parameter X2, followed by X3 and X5 parameters. All three parameters are used to quantify IGF (Eq. 2). If parameter X2 is showing the most important temporal instability for both models, it is not the case of parameter X5 with the lumped model, where it appears to be one of the least variable parameter (just after parameter X4). This result highlights the problems encountered in quantifying IGF. It seems to be the least identifiable parameter in the lumped model (with high variability of parameter X2). The problem of IGF parameter identifiability is even exacerbated with the semi-distributed model. This might be due to the high inter-dependency of parameters in the formulation of IGF (Eq. 2) in the models. Future improvements of the GRSD semi-distributed model should focus on this issue.

The most stable parameter appears to be X4 (time base of unit hydrograph), which is consistent with previous works (Lobligeois, 2014), where it has been shown that this parameter can easily be related to catchment physical characteristics, such as catchment size. 


\subsection{Spatial variability of parameters}

We also analysed the spatial variability of the parameter values, considering variability between parameters and between models. To this end, we estimated the coefficient of variation of the parameter values among catchments (one performed by calibration period). The aim is to quantify how much parameters can be different between catchments.

Similarly to the temporal variability of parameters, spatial variability appears to be higher with the semi-distributed model than with the lumped model. However, contrary to the temporal variability, spatial variability is more expected here, as one of the objectives of a semi-distributed model is precisely to consider those spatial heterogeneities of the hydrological response. However, we noticed again that parameters $\mathrm{X} 1$ and $\mathrm{X} 2$ are the most variable parameters for the semi-distributed model. Therefore they appear among the most variable parameters for both analyses, the time variability and the space variability analyses. These two parameters control water balance. Similarly to the temporal variability, they are expected to be highly variable in space in order to get along with sequential observations at each downstream station during calibration.

Spatial variabilities are not constant over time (as observed by the boxplot widths on Fig. 6). Particularly, the spatial variability of parameter X3 (capacity of routing store) is stable for the lumped model, whereas it appears to be very dependent on the calibration period for the semi-distributed model. For instance, it has the highest spatial variability during the "1984-1994" calibration period, and is among the lowest variability just 3 years after (not shown). Once again, a robustness problem of GRSD is identified and needs to be addressed in further investigations.

\section{Conclusion}

In this paper, we compared the spatio-temporal variability of the parameters of a semi-distributed model (GRSD) and a lumped model (GR5J) on which it is based. We applied a rolling calibration strategy over 21 periods and 64 French catchments.

A classical evaluation of discharge simulations using goodness-of-fit criteria was applied to the outputs of both models. It illustrates a slightly better performance of the lumped model during calibration, and similar performance of the models during validation. However, further investigation on parameter identifiability highlighted much higher temporal variabilities of the semi-distributed model. This study also showed that it is more difficult to identify catchment's specific parameter sets with the semi-distributed model than with the lumped model.

The methodology applied also enabled to identify the more unstable parameters. Results showed that the parameters related to the quantification of intercatchment groundwater flows (IGF) are the most unstable. We conclude that further modelling efforts should focus on the model structure in order to better quantify IGF.

This work also emphasizes the fact that the calibration strategy and the evaluation approach of a semi-distributed model should not focus only on goodness-of-fit performance, but also on parameter identifiability, especially if the model aims to be used to explore future scenarios in a changing world. Such an approach would also facilitate the application of the model at ungauged locations, since parameters that depict high variability in time and space might be more difficult to regionalize.

\section{Data availability}

The streamflow data used in this study are freely available at: http://www.hydro.eaufrance.fr. The climatic data are produced by Métèo-France. Information can be found at: http: //publitheque.meteo.fr.

Acknowledgements. The first author was partially funded by the French Waterboard "Agence de l'Eau Rhin-Meuse" within the MOSARH21 project (project \#15C92002). Météo-France and SCHAPI are thanked for making climatic and hydrological data available for this study. The authors thank the anonymous reviewer for his comments on the manuscript.

\section{References}

Andersen, J., Refsgaard, J. C., and Jensen, K. H.: Distributed hydrological modelling of the Senegal River Basin model construction and validation, J. Hydrol., 247, 200-214, doi:10.1016/S0022-1694(01)00384-5, 2001.

Andréassian, V., Parent, E., and Michel, C.: A distribution-free test to detect gradual changes in watershed behavior, Water Resour. Res., 39, 1252, doi:10.1029/2003WR002081, 2003.

Bentura, P. L. and Michel, C.: Flood routing in a wide channel with a quadratic lag-and-route method, Hydrolog. Sci. J., 42, 169189, doi:10.1080/02626669709492018, 1997.

Brigode, P., Oudin, L., and Perrin, C.: Hydrological model parameter instability: A source of additional uncertainty in estimating the hydrological impacts of climate change?, J. Hydrol., 476, 410-425, doi:10.1016/j.jhydrol.2012.11.012, 2013.

Brown, A. E., Zhang, L., McMahon, T. A., Western, A. W. and Vertessy, R. A.: A review of paired catchment studies for determining changes in water yield resulting from alterations in vegetation, J. Hydrol., 310, 28-61, doi:10.1016/j.jhydrol.2004.12.010, 2005.

Coron, L., Andréassian, V., Perrin, C., Lerat, J., Vaze, J., Bourqui, M., and Hendrickx, F.: Crash testing hydrological models in contrasted climate conditions: An experiment on 216 Australian catchments, Water Resour. Res., 48, W05552, doi:10.1029/2011WR011721, 2012.

Gupta, H. V., Kling, H., Yilmaz, K. K., and Martinez, G. F.: Decomposition of the mean squared error and NSE performance criteria: Implications for improving hydrological modelling, J. Hydrol., 377, 80-91, doi:10.1016/j.jhydrol.2009.08.003, 2009. 
HYDRO: http://www.hydro.eaufrance.fr, last access: May 2016.

Juston, J., Seibert, J., and Johansson, P.-O.: Temporal sampling strategies and uncertainty in calibrating a conceptual hydrological model for a small boreal catchment, Hydrol. Process., 23, 3093-3109, doi:10.1002/hyp.7421, 2009.

Klemeš, V.: Operational testing of hydrological simulation models, Hydrolog. Sci. J., 31, 13-24, doi:10.1080/02626668609491024, 1986.

Leleu, I., Tonnelier, I., Puechberty, R., Gouin, P., Viquendi, I., Cobos, L., Foray, A., Baillon, M., and Ndima, P.-O.: La refonte du système d'information national pour la gestion et la mise à disposition des données hydrométriques, La Houille Blanche, 25-32, doi:10.1051/lhb/2014004, 2014.

Le Moine, N.: Le bassin versant de surface vu par le souterrain: une voie d'amélioration des performances et du réalisme des modèles pluie-débit?, PhD thesis, Université Pierre et Marie Curie, Paris, France, 348 pp., 2008.

Lerat, J.: Quels apports hydrologiques pour les modèles hydrauliques? Vers un modèle intégré de simulation des crues, $\mathrm{PhD}$ thesis, University of Pierre et Marie Curie, Paris, France, 390 pp., 2009.

Lerat, J., Andréassian, V., Perrin, C., Vaze, J., Perraud, J. M., Ribstein, P., and Loumagne, C.: Do internal flow measurements improve the calibration of rainfall-runoff models?, Water Resour. Res., 48, W02511, doi:10.1029/2010WR010179, 2012.

Lobligeois, F.: Mieux connaître la distribution spatiale des pluies améliore-t-il la modélisation des crues?, Diagnostic sur 181 bassins versants français, PhD thesis, AgroParisTech, Paris, France, 310 pp., 2014

Lobligeois, F., Andréassian, V., Perrin, C., Tabary, P., and Loumagne, C.: When does higher spatial resolution rainfall information improve streamflow simulation? An evaluation using 3620 flood events, Hydrol. Earth Syst. Sci., 18, 575-594, doi: 10.5194/hess-18-575-2014, 2014.

Merz, R. and Blöschl, G.: A regional analysis of event runoff coefficients with respect to climate and catchment characteristics in Austria, Water Resour. Res., 45, W01405, doi:10.1029/2008WR007163, 2009.

Merz, R., Blöschl, G., and Parajka, J.: Spatio-temporal variability of event runoff coefficients, J. Hydrol., 331, 591-604, doi:10.1016/j.jhydrol.2006.06.008, 2006.

Merz, R., Parajka, J., and Blöschl, G.: Time stability of catchment model parameters: Implications for climate impact analyses, Water Resour. Res., 47, W02531, doi:10.1029/2010WR009505, 2011.

Métèo-France: http://publitheque.meteo.fr, last access: May 2016.
Moussa, R., Chahinian, N., and Bocquillon, C.: Distributed hydrological modelling of a Mediterranean mountainous catchment Model construction and multi-site validation, J. Hydrol., 337, 35-51, doi:10.1016/j.jhydrol.2007.01.028, 2007.

Nash, J. and Sutcliffe, J.: River flow forecasting through conceptual models part I - A discussion of principles, J. Hydrol., 10, 282290, doi:10.1016/0022-1694(70)90255-6, 1970.

Niel, H., Paturel, J.-E., and Servat, E.: Study of parameter stability of a lumped hydrologic model in a context of climatic variability, J. Hydrol., 278, 213-230, doi:10.1016/S0022-1694(03)00158-6, 2003.

Pokhrel, P. and Gupta, H. V.: On the ability to infer spatial catchment variability using streamflow hydrographs, Water Resour. Res., 47, W08534, doi:10.1029/2010WR009873, 2011.

Pushpalatha, R., Perrin, C., Le Moine, N., and Andréassian, V.: A review of efficiency criteria suitable for evaluating low-flow simulations, J. Hydrol., 517, 1176-1187, doi:10.1016/j.jhydrol.2011.11.055, 2012.

Reed, S., Koren, V., Smith, M., Zhang, Z., Moreda, F., Seo, D.-J., and DMIP Participants: Overall distributed model intercomparison project results, J. Hydrol., 298, 27-60, doi:10.1016/j.jhydrol.2004.03.031, 2004.

Thirel, G., Andréassian, V., and Perrin, C.: On the need to test hydrological models under changing conditions, Hydrolog. Sci. J., 60, 1165-1173, doi:10.1080/02626667.2015.1050027, 2015.

Valéry, A., Andréassian, V., and Perrin, C.: 'As simple as possible but not simpler': What is useful in a temperature-based snow-accounting routine? Part 2 - Sensitivity analysis of the Cemaneige snow accounting routine on 380 catchments, J. Hydrol., 517, 1176-1187, doi:10.1016/j.jhydrol.2014.04.058, 2014.

Verstegen, J. A., Karssenberg, D., van der Hilst, F., and Faaij, A. P.: Detecting systemic change in a land use system by Bayesian data assimilation, Environ. Modell. Softw., 75, 424438, doi:10.1016/j.envsoft.2015.02.013, 2016.

Vidal, J.-P., Martin, E., Franchistéguy, L., Baillon, M., and Soubeyroux, J.-M.: A 50-year high-resolution atmospheric reanalysis over France with the Safran system, Int. J. Climatol., 30, 16271644, doi:10.1002/joc.2003, 2010.

Wagener, T., McIntyre, N., Lees, M. J., Wheater, H. S., and Gupta, H. V.: Towards reduced uncertainty in conceptual rainfall-runoff modelling: dynamic identifiability analysis, Hydrol. Process., 17, 455-476, doi:10.1002/hyp.1135, 2003.

Wilby, R. L.: Uncertainty in water resource model parameters used for climate change impact assessment, Hydrol. Process., 19, 3201-3219, doi:10.1002/hyp.5819, 2005. 